\title{
Chile: Improving Access and Quality to Stop Social Unrest ERNESTO SCHIEFELBEIN
}

Ernesto Schiefelbein is research fellow at the Universidad Autonoma de Chile. Email: pschiefe@gmail.com.

In 2011, highly unequal income and educational opportunities triggered street demonstrations in Chile and replications in several Latin American countries. Now, Chileans want to stop civil unrest, to avoid a negative impact on its remarkable gross domestic product per capita growth rate (4\% per year in 2000 2011) and on the ongoing progress to the reduction of poverty (from 38\% in 1990 to $15 \%$ in 2009). At the beginning of 2012, polls showed a majority supporting the design of strategies to reduce social inequality and gaps in education. Fortunately, helping students to read one or two pages in their leisure time, in

order to be prepared for active engagement in class, has reduced learning gaps and increased promotion rates in pilot trials. If results are confirmed in a next large-scale trial, this strategy could help in restraining further demonstrations and provide a model for a number of Latin American countries facing similar problems.

\section{Students' Demonstrations from 2011 to the Present}

In May 2011, Chilean university students took to the streets to demand reform of the education system. They asked for a fair student-loan scheme and access 
to quality education for everyone. When the school year ended in December, there was no sign of settling the most serious confrontation with students over the past two decades in Latin America.

The top 40 percent of each age-group cohort now has access to higher education. Even though this is an impressive achievement, most of these students belong to the upper half of the socioeconomic distribution (households having an average income over US\$20,000). However, two-thirds of these families have difficulties financing the annual cost of higher education (ranging from US\$5,000 to 10,000 , per student). Financing education is especially difficult for middle social class families with more than one child, because they do not have access to affordable student loans.

Money is needed to pay for further education after high school, but previous knowledge and skills to learn new knowledge are also required to be admitted to higher education, in order for students to stay enrolled and to graduate. Being a good student in a public high school does not guarantee access to higher education. As an example, the valedictorian of a marginal urban public high school, with a high school grade average of 95 percent, only achieved 423 points in the 2011 University Selection Test—below the minimum of 450 points required to enroll at a university. Graduates from public high schools often do not have the capacity to learn university-level material. They have not reached the necessary level of intellectual development, and remedial courses cannot close this gap. These students require more individualized teaching; but this teaching cannot be provided, given the large size of classes and the lack of faculty experience with cooperative and interactive pedagogy. Therefore, only 
one of three admitted students eventually graduate in Chile, whereas the comparable ratio is 8:1 for Argentina and 2:1 for Colombia.

\section{Closing THE GAP}

The need for remedial courses in college is not unusual, but in the United States students can take remedial courses that do not count toward a degree-just delay the time to degree. A recent report found that only one-third of US students leave high school academically prepared for college (one-sixth of Hispanic students). Some studies state that as many as 40 percent of college students will take at least one remedial course.

However, in Latin America and other developing countries, university study involves the pursuit of professional degrees-such as in law, medicine, architecture, or engineering-without room in the schedule for general study or remedial work. Given that all students follow the same rigid degree program, remedial courses do not fit into schedule unless the whole first semester is allocated to them.

Fortunately, systematic help has been effective for students to gain preparation for increased engagement in each class. This is the objective of the innovation now being introduced at the first semester of Universidad Autonoma de Chile. The essential components are: (1) a clear outline and summary of topics to be covered in each class, distributed during (or before) the first class session; (2) specific text, assigned for each class (starting with less than 1,000 words in the first semester, given that students are not used to extensive reading assignments), covering the basic knowledge (definitions, concepts, or basic data) in advance in order to derive maximum benefit from the class; (3) start each class 
with an oral factual (literal) question to one student (selected at random) and assign a mark for the response to the question (as a sort of scaffolding to create the habit of reading in advance); (4) request students (immediately after the oral quiz) to ask their questions (about what they read beforehand) or to read a passage that they did not understand (an interesting discussion usually flows from their questions); (5) use the rest of the class time to deliver the lesson as the teacher prefers; and (6) provide the usual references for additional reading, after class.

Even if students do not know the exact answer (to the oral question) but can demonstrate that they read the material, they still receive 60 percent credit for answering the question. Pilot trials have shown that since the students know exactly what and how to study, it is easier for them to review the material in a productive way. They soon decide what areas they need to focus on (for example, vocabulary or meaning). This kind of freedom fosters autonomy in students and gives them responsibility for their own learning.

Faculty participating in pilot experiences has reported increased participation in class, and students polled responded that previous reading improved their learning. Therefore, it was decided to start large-scale implementation in March 2012. Syllabus and materials for the 156 courses (offered in the first semester in 26 programs) were already available on the university Web site for new students enrolled, in January 2012. Deans, program directors, and professors have participated in three practical seminars. Hopefully, this innovation will drastically reduce the number of traditional lectures and will prompt improved learning experiences. 
To limit confusion, only a few key changes will be implemented in each semester. Samples of incoming students in each first semester course will be reporting day-by-day (during the first three weeks) about the way the class starts (oral question and grading the response). Later on, program directors will talk with professors who forget to implement such a key change. The innovation will be implemented in ensuing semesters, with a similar sequence.

The impact of this strategy will be carefully evaluated at the end of June 2012. It is hoped that the rest of Chilean universities will take advantage if proven successful. Throughout Latin America, university first-year dropout rates average at 50 percent. It is estimated that about one-third of the 10 million underachieving Latin American university students (lacking required skills and knowledge) could also benefit from this low-cost treatment and keep moving forward in their academic careers. 